\title{
Historiografias de um epicentro da pobreza
}

\section{Historiographies from an epicenter of poverty}

Resenha da obra: RÜCKERT, Fabiano; et al (Orgs.). Histórias da pobreza no Brasil. (Coleção Direito e Justiça Social; 6). Rio Grande: Ed. da FURG, 2019. 410p.

Nathalia Claro Moreira*

A deflagração do estado de calamidade pública causado pela pandemia do Covid-19 trouxe à tona a reflexão sobre o complexo e multidimensional fenômeno da pobreza em países como o Brasil. A pandemia emergiu a necessidade de o Estado brasileiro intervir com um programa de assistência social provisório (medida contrariada e segurada até a último fôlego pelo presente Governo) de modo a conter o impacto do desemprego e da retração econômica gerada pela quarentena. Fato curioso é que este cenário instável forçosamente gerou um efeito colateral positivo, embora efêmero: a redução da taxa de extrema pobreza com a distribuição das parcelas do auxílio emergencial, a mais relevante diminuição ocorrida em quatro décadas conforme dados recentes da Fundação Getúlio Vargas (FGV, 2020). Por outro lado, o término deste auxílio emergencial, previsto para o final deste ano, já indica um retorno absurdo do fenômeno: cerca de 15 milhões de brasileiros serão devolvidos para a miséria, consequentemente devolvendo ao Brasil a trágica alcunha de "epicentro emergente da fome extrema".

Neste cenário distópico, a leitura do livro "Histórias da Pobreza no Brasil" (Ed. FURG, 2019), volume 6 da Coleção Direito e Justiça Social, se torna praticamente obrigatória. Organizado pelos professores e pesquisadores Fabiano Quadros Rückert, Jonathan Fachini da Silva, José Carlos da Silva Cardozo e Tiago da Silva Cesar, a proposta da publicação foi compor uma obra que contemplasse diferentes escalas de análise sobre a pobreza associadas as particularidades históricas e socioeconômicas desde o Norte ao Sul do Brasil.

\footnotetext{
* Possui Graduação em História pela Universidade Federal de Mato Grosso do Sul (2018). É Mestra pelo Programa de Pós-Graduação em Educação do Campus Pantanal (PPGE/UFMS). Doutoranda em Filosofia pela Universidade do Estado do Rio de Janeiro (POSFIL/UERJ).
} 
Uma historiografia do cotidiano da pobreza e das representações da pobreza em diferentes estados brasileiros são os aportes comuns deste livro. $\mathrm{Na}$ esteira da história das coletividades, os 14 capítulos revelam os aspectos intrínsecos a construção histórico-social da condição de miséria dentro de classes marginalizadas, isto é, trabalhadores pobres, escravizados, encarcerados, órfãos, mestiços, desabrigados. A obra desnaturaliza a percepção das desigualdades sociais a partir do momento em que esmiúça as particularidades dos grupos envolvidos pela pobreza. E, neste aspecto, sinaliza a continuidade da abordagem historiográfica dos "excluídos" - uma abordagem que recebeu contribuições de historiadores como Michelle Perrot, Laura de Melo e Souza, José do Amaral Lapa e Sandra Jathay Pesavento, dentre outros (PERROT, 1988; SOUZA, 1986; PESAVENTO, 2001; LAPA, 2008). Buscando a diversidade dos "excluídos", o exercício historiográfico dos autores remonta um delicado trabalho de análise de fontes documentais variadas como processos judiciais, relatos de viajantes, jornais, petições, leis, estatísticas sanitárias, documentos eclesiásticos, relatórios da administração pública e obras literárias.

O intenso capítulo que abre o livro, de autoria de Flavio José Gomes Cabral, nos conduz as cercanias do povoado de Bonito, em Pernambuco, durante os Setecentos. Com destreza, o autor nos apresenta com riqueza de detalhes a descrição de uma devassa (termo jurídico que quer dizer apuração de ato criminoso) contra um grupo de trabalhadores pobres instalados no referido povoado. As descrições históricas utilizadas pelo autor estão encerradas em uma vasta documentação disposta no Arquivo Nacional: manuscritos de teor diverso (depoimentos, relatórios de espionagem, correspondências entre autoridades da região) que versam sobre a contenda. A questão central do texto não é questionar a veracidade do ato criminoso que teria gerado a devassa (conforme os autos, o inquérito teria sido instaurado diante da preocupação de que houvesse entre aqueles pobres um ímpeto revolucionário), mas sim, dar conhecimento da história de vida destes personagens marginalizados caracterizados no imaginário da época como "desclassificados".

A mesma destreza demonstra Divino Senna em sua investigação sobre o 'ser pobre” no antigo Mato Grosso. O autor se utiliza da análise das palavras "pobre" e "pobreza" nos Relatórios de Presidentes de Província, nos Processos 
Judiciais, nas Leis Provinciais e nos Periódicos publicados até meados do século XIX, a fim de interpretar a caracterização da pobreza no imaginário social da época. Quem era o pobre até meados do século XIX? - questiona Senna às fontes, cuja resposta, de certo extensa, é difícil sintetizar em breve descrição: nos periódicos Jornal Echo Cuiabano e Jornal A Imprensa de Cuyaba, pobres eram aqueles "a quem deveria ser direcionado auxílio financeiro, material ou espiritual” (SENNA, 2019, p. 45); nos Relatórios de Presidentes e Vice Presidentes da Província de Mato Grosso, os pobres eram "que dependiam da alimentação fornecida pelos cofres públicos”. Ainda, eram aqueles que não sabiam assinar o próprio nome, distantes de uma formação educacional, sendo, não raramente, "refém dos mandos e desmandos de autoridades e/ou proprietários" (SENNA, 2019, p. 45). O texto se desenvolve em um ritmo de contraposição de discursos e caracterizações da pobreza de um mesmo local/época, denotando elementos que auxiliam o leitor a compreender que o fenômeno da pobreza é, por fim, multidimensional.

Adiante, a narrativa da desigualdade social na arquitetura é o aporte fundamental que norteia os capítulos de José Newton Coelho Meneses e Maria da Conceição Pinheiro de Almeida. Com uma aguçada análise, Meneses coteja as descrições do naturalista Auguste de Saint-Hilaire em sua passagem pela Vila de Ibitipoca, durante uma segunda viagem do Rio de Janeiro a Minas Gerais, em 1822. As memórias e anotações do naturalista se prendem aos aspectos e distinções arquitetônicas entre os domicílios das classes ricas e pobres da vila visitada, denotando contradições e encontros de classes a partir da estética. Almeida, por sua vez, se dispõe a analisar em seu capítulo a relação entre a moradia dos pobres em São Luís do Maranhão e o serviço sanitário. A autora nos demonstra detalhadamente que o serviço sanitário desenvolvido no Maranhão, durante a Primeira República, tinha a finalidade de sanear os ambientes considerados insalubres, aqueles ocupados pelas camadas subalternas da população urbana.

O capítulo de Josali do Amaral privilegia a relação entre a pobreza e sua ambiência. Amaral percorre a trilha dos rios amazônicos para abordar a intensificação do fenômeno da pobreza como resultado das tentativas de modificação das relações de produção que foram conduzidas pelo Império do 
Brasil, em meados do século XIX. A sazonalidade da floresta amazônica e suas singularidades geográficas lograram poucos estudos pela historiografia, e deste modo a autora assume uma postura de desbravadora de uma historicidade ainda bem desconhecida: a pobreza amazônica derivada das tensões do projeto agroexportador no final do Segundo Reinado. $O$ foco da autora é direcionado para a caracterização dos pobres desta região/temporalidade a partir da análise de expedientes e correspondências remetidas por autoridades administrativas. Deste modo procede ao cotejamento de uma carta do presidente da Província do Amazonas, Adolfo de Barros Cavalcante de Albuquerque Lacerda, em 1884, em que a autoridade caracteriza os pobres caboclos ribeirinhos da Amazônia a partir da expressão latina Primus Capientis. Uma expressão “sutil” e ao mesmo tempo simbólica, denota a autora, para se referir ao trato dos ribeirinhos com a terra, denotando a oposição dos pobres daquela região à modernização econômica que ansiavam os dirigentes do reinado - e que, aliás, anseiam, ainda hoje, os dirigentes deste país.

Ainda nas ambiências da pobreza, o capítulo de Frederico de Castro nos conduz pelos caminhos que levavam à Fortaleza, em 1877, cujas paisagens formavam um retrato trágico: a seca, a fome, a miséria e a morte eram símbolos da capital de um "reino pavoroso". O autor revela ao leitor as minucias da triste vida dos retirantes entre os anos de 1877 a 1880 a partir das crônicas de Rodolpho Theopilo - um dos capítulos mais dolorosos, é verdade, denotando o paradoxo tão bem ilustrado pelo cronista da época de uma "sociedade que moderniza, mas que, ao mesmo tempo, produz seus próprios "bárbaros", os quais, sempre famintos e quase sempre revoltados" (THEOPHILO, 1992 apud RÜCKERT et al, 2019).

Da seca nordestina aos frios cárceres sul-rio-grandenses, a leitura seguinte do capítulo de Tiago da Silva Cesar nos leva ao ínterim do sistema burocrático do Brasil Imperial e destaca a prática peticionária (um instrumento de reclamação direta dos súditos aos reis). A partir de um conjunto de petições de encarcerados do recinto Penal da Casa de Correção de Porto Alegre, o autor faz uma análise da linguagem destes presos miseráveis a partir dos documentos. Conforme o autor, embora possuíssem escritas diversas, todas as petições possuíam uma linguagem de subserviência e encerravam com uma clássica fórmula de fechamento: "Espera 
Receber Mercê”. A leitura das petições, todavia, para além de uma resignação com o estado de encarcerado, denota ao leitor que os presos buscavam artifícios para mitigar a miséria ao qual eram submetidos dentro do recinto penal, reclamando direitos individuais e civis básicos.

Ainda nas franjas ao sul do Brasil, Denize Terezinha Leal Freitas e Jonathan Fachini da Silva retiram os leitores dos documentos penais e nos conduzem aos manuscritos eclesiásticos da Freguesia de Madre Deus de Porto Alegre, entre os séculos XVIII e XIX. O objetivo dos autores é historicizar sobre a pobreza entre as mulheres solteiras (ou não casadas conforme o modelo tridentino), arrolando o estudo na seara da História da Família. A análise da documentação é realizada a partir de um conteúdo, em sua grande parte, quantitativo: número/gênero de confessos da freguesia, de agregados, de viúvos/viúvas, valores de salários das mulheres que trabalhavam, etc., o que demandou dos autores uma interpretação mais exaustiva das fontes. O objetivo do texto se volta a compreender o lugar das mulheres pobres nesta região/temporalidade, ressaltando, de certo modo, a agência destas mulheres e os pormenores de sua atuação social. Além disso, o capítulo ressalva ponto importante sobre o fenômeno: muitas mulheres pobres advinham de família nobre ou tinham boas rendas, porém a viuvez ou o abandono dos esposos, somado à dividas que estes mesmos maridos deixavam, logravam-lhes uma situação difícil que, por vezes, alcançava a miséria. Neste sentido, concluem os autores que "a pobreza não se restringia a apenas um grupo de pessoas, mas também estava à espreita daqueles que nunca tiveram que lutar pela sobrevivência".

Na sequência, Paulo Roberto Staudt Moreira concede visibilidade a vivência de um ex-escravizado, ou, "um forro", chamado de "o preto" Pedro Garibaldi. Sob o prisma da pobreza, Moreira analisa o caso envolvendo o exescravizado Pedro e o imigrante branco Carlos Dihl, a partir da descrição da contenda registrada em um documento judicial. A situação se estabelece no mercado público de Porto Alegre, capital da província de São Pedro do Rio Grande do Sul, no século XIX. A briga em si - um não-raro caso de racismo no qual o ex-escravizado e açougueiro, Pedro, foi agredido pelo cliente branco aos tapas e injúrias pela qualidade da carne - não é exatamente o foco da análise de 
Moreira, mas são os detalhes do registro histórico que nos trazem percepções interessantes sobre a vivência dos forros: as particularidades do nome de Pedro, chamado de Pedro Garibaldi, uma possível referência ou homenagem do exescravizado à Guerra Civil farroupilha; o uso de expressões incomuns pelo forro para ofender o cliente racista (expressões que poderiam denotar práticas homossexuais por parte do branco), o fato deste Carlos Dihl não ser reconhecido como brasileiro pelos negros que testemunham a briga, mas ser considerado "o estrangeiro" (o que denotaria o acionamento de uma identidade nacional pelos ex-escravizados), dentre outros aspectos tão bem interpretados e provocados pela astúcia do autor do capítulo que nos permitem fugir das análises mais triviais das documentações históricas e ainda, das mais triviais interpretações sobre os forros e da própria pobreza destes sujeitos.

Como Moreira, Arilson dos Santos Gomes ilumina a historiografia sobre as identidades negras no Brasil, por sua vez apontando as lentes de análise para a região amazônica, mais precisamente ao sudeste do Pará, para a cidade de Marabá, no início do século XX. Conforme o autor, a cidade possui um imaginário popular de contradições e estereótipos racistas contra a pequena população preta ou parda (chamada de modo pejorativo de "maranhense"). O estigma racista notoriamente tem origens na fundação da cidade que emergiu de uma tensão inter-étnica - tensão esta que logrou a eliminação de segmentos indígenas inteiros durante a formação do estado de Tocantins. Neste sentido, Gomes habilmente interpreta o jogo de representações das identidades negras nos principais jornais de Marabá entre 1913-1983 (trazendo, ainda, recortes fotográficos de suas personagens históricas que saciam a ânsia de um leitor mais exigente com estes preciosos detalhes), na intenção de denotar as agências históricas do grupo social negro a partir da recuperação biográfica de personagens negros importantes como José Elias Monteiro Lopes, primeiro juiz de Marabá - um doutor negro -, o vereador José Curcino de Azevedo e o líder da Guerrilha do Araguaia, Osvaldo Orlando da Costa.

O décimo-primeiro capítulo de José Carlos da Silva Cardozo aborda uma categoria simbólica do fenômeno da pobreza: os órfãos. Cardozo perfaz o percurso histórico do estabelecimento da instituição jurídica Juízo dos Órfãos em Porto Alegre, com ênfase na atuação do órgão nos primórdios do século XX. A 
análise procede sobre o processo judicial de tutela envolvendo as famílias Escobar e Barcellos Pinheiro - de um lado, a família de um rico desembargador sem filhos, de outro, de uma mulher solteira pobre que falece precocemente de tuberculose e deixa uma menina de 02 anos. A falecida, que havia trabalhado para o desembargador como empregada e levado a filha para conviver com a família do patrão por algum tempo, não poderia imaginar que os Escobar iniciariam um longo processo judicial para ter a guarda da criança. Após a morte da mãe, a menina ficou aos cuidados da família materna cujas condições sociais eram bem distantes da riqueza do desembargador. Não é preciso dizer muito: a riqueza e a influência da família Barcellos consegue facilmente tirar a guarda da criança de seus parentes maternos - uma espécie de compra da criança. Uma longa briga judicial se segue, com a reclamação da família de sangue por seus direitos, obstaculizados, porém, pelos percalços da desigualdade de classes.

No capítulo escrito por Fabiano Quadros Rückert, o binômio urbanização/pobreza é a ênfase da prospecção bibliográfica realizada pelo autor que concentrou sua atenção no contexto de transição do século XIX para o XX. A difícil revisão temática busca contrapor as diferentes narrativas historiográficas sobre a pobreza selecionadas pelo autor em espaços decisivos da recente república: as cidades do Rio de Janeiro - então capital nacional - e as cidades paulistas de Campinas, Taubaté, Franca, Rio Claro e São Paulo, isto é, as "terras do café”. A análise encontra pouco consenso sobre a caracterização da pobreza, reforçando a ideia do livro de que a pobreza é um conjunto heterógeno e multidimensional. Por outro lado, Rückert consegue identificar dois eixos teórico-metodológicos que norteiam a reflexão da pobreza na historiografia analisada: o primeiro, diz respeito aos dispositivos de controle do espaço urbano acionados pelo poder público e aos interesses envolvidos nas iniciativas de modernização urbana promovidas pelas elites brasileiras; o segundo eixo diz respeito à presença dos pobres nos diferentes espaços da cidade e ao papel que exerciam na economia urbana.

Adiante, a relação entre a pobreza e os desastres naturais é historicizada por Alfredo Ricardo Silva Lopes. O autor investigou este tema na região sul de Santa Catarina, na tentativa de problematizar as representações dos jornais locais sobre os indivíduos afetados pelas enchentes ocorridas no ano de 1974. O 
trabalho se ancora nas ponderações teórico-metodológicas do historiador Greg Bankoff que estabelece uma relação entre os desastres naturais e a cultura. Conforme Lopes, o momento do desastre em Santa Catarina, suspendeu temporariamente a divisão de classes na população - fato que nos faz refletir sobre essa "massificação efêmera" em momentos trágicos e a ideia de que tragédias similares são capazes de surtir mudanças na estratificação social (fato que também observamos durante a atual pandemia do Covid 19). Todavia, esta suspensão de classes sociais é uma máscara retirada no pós-desastre, e logo que a cortina se abre o jogo de segregações retorna: no caso de Santa Catarina, a calamidade de 1974 foi se intensificando à medida que os pobres passaram perceber as desigualdades instituídas no processo de recuperação da cidade.

No encerramento da obra, o capítulo de Helder Remigio de Amorim perfaz o caminho da publicação do livro Geopolítica da Fome, ensaio mundialmente conhecido de Josué de Castro sobre o fenômeno da fome generalizada em tempos de globalização. Amorim, por sua parte, realiza uma interessante investigação sobre a recepção da obra no Brasil em meio ao clima de tensão anticomunista, denotando aspectos biográficos relevantes do intelectual Josué de Castro - desde sua atuação política enquanto deputado federal do Partido Trabalhista Brasileiro (PTB) de Pernambuco, na década de 1950, aos reveses do golpe militar que cassaram seus direitos e o obrigaram a pedir asilo internacional (foi acolhido na França, atuando como professor universitário e membro de pesquisa do Centro Internacional para o Desenvolvimento (CID)). O texto de Amorim nos lembra que a pobreza, e consequentemente, a fome são, estruturalmente, projetos históricos de manutenção das classes dominantes e que, portanto, a mitigação dessas mazelas derivadas das desigualdades sociais só se efetiva a partir da participação e da reflexão política.

A compreensão das desigualdades sociais no Brasil se faz necessária, e mais do que uma análise de nosso presente histórico, a tarefa demanda uma atenciosa investigação do passado, das dinâmicas e vivências de diferentes grupos culturais e sociais que integram os extratos históricos do fenômeno da pobreza. Em um país de dimensão continental, é mais do que esperado que o fenômeno tenha raízes, troncos e galhos com características próprias, comungando, todavia, de um solo comum: um passado colonial repleto de violências, genocídios e 
explorações externas; um Império governado por uma elite conservadora e escravista; e uma República frágil que nasceu e cresceu assombrada pelos problemas herdados do passado.

\section{Referências bibliográficas}

FGV - Fundação Getúlio Vargas Social. (2020). Qual foi o impacto da crise sobre a pobreza e a distribuição de renda? Disponível em: https://cps.fgv.br/Pobreza Desigualdade. Acesso: 20 de setembro de 2020.

LAPA, José Roberto do Amaral. Os excluídos. Contribuição à História da Pobreza no Brasil (1850-1930). São Paulo: EDUSP/Campinas: Editora Unicamp, 2008.

PERROT, Michelle. Os excluídos da História: operários, mulheres e prisioneiros. São Paulo: Paz e Terra, 1988.

PESAVENTO, Sandra Jathay. Uma outra cidade. O mundo dos excluídos no final do século XIX. São Paulo: Companhia Editora Nacional, 2001.

SOUZA, Laura de Mello e. Desclassificados do ouro: a pobreza mineira do século XVIII. 3ed. Rio de Janeiro: Graal, 1986.

Recebido em Outubro de 2020 Aprovado em Dezembro de 2020

DOI: $\underline{\text { https://doi.org/10.14295/rbhcs.v13i25.12253 }}$ 